\title{
Exploring the causal relationship between the antecedents and consequences of talent management for early career academics in South African higher education institutions
}

Authors:
Dorcas L. Lesenyeho' ${ }^{1}$
Nicolene E. Barkhuizen ${ }^{1}$
Nico E. Schutte ${ }^{1}$
Affiliations:
${ }^{1}$ Global Innovative Forefront
Talent, Research Niche Area,
North-West University,
South Africa
Corresponding author:
Nicolene Barkhuizen,
nicolene.barkhuizen@
nwu.ac.za
Dates:
Received: 12 Feb. 2017
Accepted: 12 Apr. 2018
Published: 12 July 2018
How to cite this article:
Lesenyeho, D.L., Barkhuizen,
N.E., \& Schutte, N.E. (2018).
Exploring the causal
relationship between the
antecedents and
consequences of talent
management for early career
academics in South African
higher education institutions.
SA Journal of Human your
Resource Management/SA
Tydskrif vir
to read online.
Menslikehulpbronbestuur,
16(0), a912. https://doi.
org/10.4102/sajhrm.
v16i0.912
Copyright:
@ 2018. The Authors.
Licensee: AOSIS. This work
is licensed under the
Creative Commons
Attribution License.

Orientation: South African public higher education institutions (HEIs) are facing significant challenges to attract and retain quality early career academics. Therefore, the need exists to explore the potential antecedents and consequences of effective talent management practices for early career academics.

Research purpose: The objective of this study was to explore the causal relationship between the antecedents (i.e. talent attraction; management support) and consequences (organisational commitment; intention to quit) for early career academics employed in selected South African public HEIs.

Motivation for the study: Research using a holistic approach for the effective talent management of early career academics is lacking.

Research approach/design and method: Quantitative data were gathered by administering a Talent Attraction Tool, a Talent Development Measure, a Talent Retention Diagnostic Tool and the Organisational Commitment Measure, using a sample of early career academics in public South African HEIs $(N=117)$.

Main findings: The results showed that management support, talent development, compensation and recognition, and satisfaction with institutional practices significantly enhances the organisational commitment of early career academics and reduces their turnover intentions.

Practical/managerial implications: The results highlight the importance of management support in enhancing the effective application of talent management practices among early career academics. Higher education managers are encouraged to implement talent development opportunities and adequate compensation and recognition practices to retain early career academics.

Contribution/value-add: The research provides useful information on how talent management practices can be effectively applied to enhance the commitment and retention of early career academics.

\section{Introduction}

Higher education institutions (HEIs) are finding it increasingly difficult to attract and retain skilled, innovative and talented individuals in the global war for academic talent (Mokgojwa, Barkhuizen, \& Schutte, 2017). The lack of younger individuals entering South African HEIs is concerning and can hinder its future stability and contribution to a developing country (The South African Council on Higher Education, 2014). The changing context of academia further challenges early career academics to understand and negotiate their career pathways (Price, Coffey, \& Nethery, 2015). Clearly, it becomes the responsibility of institutions of higher learning to ensure that they address the dilemmas experienced by academics in their early career phase (Makondo, 2014; Onah \& Anikwe, 2016).

The effective talent management of early career academics is important for several reasons. Firstly, globalisation has resulted in many South African scholars leaving the country for greener pastures elsewhere (Makondo, 2014). South African higher education will soon be facing a critical shortage of academic skills, if no succession planning is done to provide academics who can fill these positions 
(Robyn \& Du Preez, 2013). Secondly, many older-generation academics will be retiring soon. A report by the Department of Higher Education and Training (2015) shows that more than 2500 academic staff members will retire within the next 3-5 years from South African public HEIs. Further estimates show that more than 6000 new academics will be required in the next five years to cater for increased student numbers and to replace staff who retire. The absence of a pipeline of upcoming scholars will result in a critical loss of knowledge because of a lack of transfer of knowledge from seasoned academics (Pienaar \& Bester, 2008). Thirdly, there is a great deal of evidence to suggest that HEIs do not compensate early career academics adequately (Onah \& Anikwe, 2016). Research by Higher Education South Africa (2014) showed that academics employed as junior lecturers and lecturers earned moderately less than their counterparts in the public sector. Younger generation employees are likely to leave higher education for better rewards and benefits (Erasmus, Grobler, \& van Niekerk, 2015). Higher Education managers are therefore challenged to develop innovative talent management strategies that will attract and retain early career talent.

\section{Purpose of the study}

A truly holistic perspective on talent management for academic staff is still lacking, which limits higher educational management to effectively manage the careers of early career academics from start to finish (Saurombe, 2017). This research attempts to provide a holistic perspective on the talent management of early career academics by exploring the causal relationships between the antecedents of talent management (i.e. talent attraction, management support), talent management practices (i.e. talent development, compensation and recognition, institutional practices) and consequences of talent management (i.e. intention to quit; organisational commitment).

Currently there is no agreement on the classification of early career academics. McAlpine and Akerlind (2010) highlighted the difficulties in terms of determining who early career academics are and their development as academics. Historically it was believed that early career academics include those within their first five years of appointment (Bazeley, 2003). Others view early career scholars as ranging from post-doctoral researchers or teaching fellows, probationary academics, pre-tenured faculty members, to $\mathrm{PhD}$ students with teaching responsibilities (Gale, 2011). Consequently, the diversity of definitions and opinions regarding early career academics makes it difficult to pinpoint the exact years of tenure and qualifications required for novice scholars. Bosanquet, Melly, Matthews and Lodge (2017) argue that the employment context in higher education necessitates the redefinition of 'early career' in academia.

For purposes of this research we regarded early career academics as those who had between 1 and 15 years' work experience in higher education and were employed as a junior lecturer, lecturer or senior lecturer. Our classification was based on the unequal application of promotion practices in South African HEIs (Bitzer, 2009), blurred differentiation between academic job levels (Mouton, Louw, \& Strydom, 2013) and historical racial imbalances (Archer, 2017).

This research article is structured as follows. First a literature review is presented on the antecedents and consequences of talent management for early career academics. This is followed by a discussion of the research method applied in this study and the results. This article concludes with a discussion of the results and the recommendations for practice and further research.

\section{Literature review}

\section{Talent management defined}

Talent management involves the implementation of integrated human resource management (HRM) strategies to attract, develop, retain and productively utilise employees 'with the required skills and abilities to meet current and future business needs' (Kontoghiorghes \& Frangou, 2009). It is a culture that contributes to and unleashes the passion, commitment and performance of people, which in turn contributes to the organisation achieving its mission, vision and business goals (Barkhuizen \& Stanz, 2010). HEIs should create a talent culture conducive for the achievement of multiple priorities relating to the working environment, such as recruitment and retention, performance management, succession planning and engagement, and should ensure that these become strategic talent management imperatives (Pienaar \& Bester, 2008; Netswera, Rankhumise, \& Mavundla, 2005).

\section{Talent management models for higher education institutions}

Barkhuizen and Schutte (2016) developed the comprehensive talent life-cycle model that can be used to guide the entire process of talent management in higher education. This model proposes that talent management starts with a higher educational leadership mindset and commitment towards academic talent. Flowing from that, institutions of higher learning need to prepare their branding to attract talented scholars. Once acquired, talented individuals should be mapped and fitted into the positions that best meet their skills, to further ensure their engagement with and commitment to the workplace. Effective talent development opportunities and proper performance management systems should be put in place to ensure the career growth and subsequent retention of talent.

Barkhuizen (2014) developed a model that can be used to guide strategic talent management in HEIs. According to the Strategic Talent Management model, an integrated talent management strategy needs the human resource strategy and business strategy of HEIs to be aligned. Once this is in place, higher education can focus on attracting and recruiting a desirable pool of talent. Higher education also needs to develop a brand that will attract the right employees (Saurombe, Barkhuizen, \& Schutte, 2017). 
Furthermore, HEIs need to acknowledge and value talented individuals as a key resource. The right people need to be selected and deployed in suitable positions. Thereafter, sound talent management practices, specifically talent development, rewards and performance management, should be maintained through continuous management commitment (Mokgojwa et al., 2017). Appling talent management practices effectively leads to reduced turnover and improved individual outcomes in terms of the psychological contract, specifically work engagement, vigour, job satisfaction and motivation (Barkhuizen, 2015). This in turn has a positive influence on organisational outcomes, such as increased service quality and performance, which eventually lead to overall organisational success.

Saurombe (2017), in her study among higher educational management, developed the Talent Value Proposition Model to assist with the effective talent management of academic staff. The model depicts the following aspects, all of which collaborate towards the establishment of a talent value proposition for academic staff:

- organisational brand (consisting of reputation and image, culture and identity, strategic vision, corporate social responsibility, and work environment and surrounds)

- employment brand (consisting of fringe benefits, incentives and remuneration; leadership and managerial support; worklife balance; management and development of performance; occupational health and safety, job security; and fulfilment and purpose)

- talent life-cycle.

At last, the model depicts that after the organisational brand, employment brand and talent life-cycle processes have unfolded within the institution, these concepts then collaborate towards the establishment of a talent value proposition for academic staff members. In order for this talent value proposition to be most effective, it must take the following elements into consideration: the importance of having a talent value proposition, the mutual expectation involved in a talent value proposition, as well as the challenges involved in implementing a talent value proposition.

\section{Antecedents of talent management}

For purposes of the present study, the antecedents of talent management are identified as management support and talent attraction practices.

\section{Management support}

Management's mindset is important for the effective management of talent in organisations. According to McArdle and Ramerman (2008), management commitment towards talent unleashes the passion, commitment and performance of people, which in turn contributes to the organisation achieving its mission, vision and goals. According to Garrow and Hirsh (2008), most senior managers have a tendency to support a programme that is aligned with the business strategy. The business strategy serves as a guide for the organisation's choice of the kind of talent to attract, develop and retain in order to have correctly skilled, committed and engaged employees to deliver excellent services or quality goods (Armstrong, 2006). Human resource and talent managers are tasked to align human capital and business strategies to ensure the successful implementation of any talent management model (Schutte, 2015).

A study by Theron, Barkhuizen and Du Plessis (2014) showed that academic staff experienced sufficient support from their managers but felt that performance management and feedback needed improvement. In contrast, Netswera et al. (2005) found that HEI managers were more focused on profits, business sustenance and justification for spending, whereas employees were driven by introverted interests, such as development, monetary rewards and personal fulfilment. According to Phillips and Connell (cited in Pienaar \& Bester, 2008), top management underestimates the value and gravity of talent retention, and consequently the reasons for and solutions to labour turnover are not correctly identified.

\section{Talent attraction}

According to Myburgh (2015) a solid employer-branding component is the foundation of talent attraction. A study by Botha, Bussin and De Swart (2011) showed that factors such as employee value proposition, people strategy, brand consistency, communication of employer brand and measurement of employer brand efforts are important for the attraction of prospective talent to organisations. Selesho and Naile (2014) found that the reputation of the academic profession in society attracts potential scholars to HEIs. Onah and Anikwe (2016) postulated that a conducive learning and working climate, job flexibility, recognition, rewards and compensation, and effective employee training and development will attract academics to HEIs. A study by Makondo (2014) showed that professional support, remuneration and teaching load contribute to the attraction of academic staff.

\section{Talent management practices}

For purposes of the study, talent management practices are divided into talent development, compensation and recognition, and institutional practices.

\section{Talent development}

Talent development refers to a process of providing individuals with an opportunity to grow through challenging experiences, coaching and mentoring ( $\mathrm{O}^{\prime}$ Callaghan, 2008). According to Garrow and Hirsh (2008), organisations should develop employees who will be able to advance in their careers. Phillips and Edwards (cited in Mukweyi, 2016) maintain that, when organisations develop their people's talent, the overall talent pool increases and the war for talent decreases. 
The importance of talent development opportunities for academic staff is well documented. Singh (2015) found that the availability of talent development resulted in an increased number of accredited publications by staff members, an increased number of staff with doctorates, increased awareness of funding opportunities and increased postgraduate supervision output. Studies by Busch and Ledingham (2016) and Selesho and Naile (2014) showed that a lack of infrastructure for talent development and a lack of talent development opportunities were key factors in the turnover intentions of early career academics.

\section{Compensation and recognition}

Smit, Stanz and Bussin (2015) emphasised the need to develop and implement a relevant compensation and reward strategy for effective talent management. According to Munsamy and Bosch Venter (2009), non-monetary factors should not be overlooked, as these might also have an impact on the retention and attraction of employees. Remuneration practices are important factors in the attraction and retention of new academics, especially from historically disadvantaged ethnic groups in South Africa (Netswera et al., 2005). In South Africa, there is a critical need for black academics who can make contributions to their disciplines and professional associations, and through publications address matters of national concern (Nkomo, in Bitzer, 2008).

\section{Institutional practices}

The retention of academic staff is affected by various institutional shortcomings, such as a lack of mentorship, a lack of adequate state and research funding, uncompetitive research incentives and employment equity initiatives (see Bitzer, 2008; Netswera et al., 2005). Over the past two decades, state and private sector research funding of public universities has significantly declined (De Villiers, \& Steyn, 2009). As a result, public university academics have been compelled to become 'academic capitalists' and to generate a third stream of income that will benefit the individual and the institution (Ntshoe, Higgs, Higgs, \& Wolhuter, 2008).

According to Deem (cited in Ntshoe et al., 2008), academic staff of publicly funded universities operate in an increasingly competitive environment, deploying their academic capital, which may comprise teaching, research, consultancy skills or other applications of form academic knowledge. The work of academics has thus become more emotionally demanding and fragmented, which implies a loss of professional autonomy, scholar identity and psychological ownership (Bitzer, 2008). This could result in academic careers becoming less attractive and public HEIs not being preferred employers.

\section{Consequences of talent management}

The present research focused on organisational commitment and turnover intentions as outcomes of talent management.

\section{Organisational commitment}

Organisational commitment continues to be one of the most frequently researched attitudinal variables in the workplace with which to understand human behaviour. Porter, Steers, Mowday and Boulian (1974) originally defined organisational commitment as 'the relative strength of an individual's identification with and involvement in a particular organisation'. Allen and Meyer (1990) expanded on the theory of Porter and colleagues by conceptualising organisational commitment as a three-dimensional construct consisting of the following dimensions: affective commitment (i.e. the extent to which an employee identifies with the organisation and enjoys being part of the organisation), continuance commitment (i.e. the extent to which an employee believes he or she should remain with the organisation, because he or she made an investment in the organisation) and normative commitment (i.e. the extent to which an employee feels obliged to remain with the organisation).

Mohamed and El-Shaer (2013) postulated that the strength of the academic profession depends on the commitment of its members. These authors further stated that professional commitment can assist academic staff to persist in their profession and to develop specialised skills. According to Hundera (2014), the extent to which academics are satisfied with aspects such as work in general, their supervisor, co-workers, compensation and promotion could have a significant impact on their level of organisational commitment.

\section{Intention to quit}

According to Schlecther, Syce and Bussin (2016) it is continuously important for organisations to adopt turnover risk management strategies to ensure organisational stability and promote the effective retention of employees. Intention to quit is regarded as the most immediate determinant factor of the actual behaviour of employees (Barkhuizen \& Rothmann, 2006). Voluntary turnover intentions of academic staff have emerged as a significant problem for South African HEIs (Theron et al., 2014). A study by Barkhuizen, Schutte and Nagel (2017) showed that talent management practices such as talent acquisition, talent deployment, talent development, executive support and remuneration were significant predictors of academic staff turnover intentions. According to Pienaar and Bester (2008) labour turnover of academics has negative consequences for HEIs in terms of the loss of knowledge and experience and the time and cost related to training novice academics.

\section{Toward a hypothesised model for this study: Relating talent antecedents, practices and outcomes}

The relationship between talent management practices and turnover intentions is well documented. A study by Theron et al. (2014) showed that more than half of academics considered quitting their jobs for better compensation elsewhere. Other studies found that a lack of talent management practices relating to talent development and performance management exacerbated employees' intentions to quit their jobs in 
government institutions such as HEIs (Barkhuizen, Diseko, \& Schutte, 2015; Magolego, Barkhuizen, \& Lesenyheo, 2013; Mpofu \& Barkhuizen, 2013). Research has shown that practices relating to talent attraction, such as a lack of preparation for talent, poor recruitment, poor workforce planning and ineffective talent deployment, are significant predictors of employees' intentions to leave an organisation (Pienaar, 2013; Veldman, 2011). Onah and Anikwe (2016) found that the brain drain, the gender pay gap, unattractive salaries and a lack of adequate training are important factors that hamper the attraction and retention of academic staff.

A lack of management support towards talent has been consistently linked to high turnover intentions of employees (Barkhuizen, 2014). Barkhuizen, Welby-Cooke, Schutte and Stanz (2014) found that executives do not spend sufficient time strengthening talent pools and are not trained in the best practices and latest techniques to develop, mentor and nurture talent. On the other hand, the availability of supervisor support has been found to enhance the affective commitment of part-time academic staff members (Matata, Elegwa, \& Maurice, 2014; Mohamed \& El-Shaer, 2013).

Studies have also highlighted the positive effects of talent management on academic staff, if effectively applied. According to Joiner and Bokalis (2006), factors such as role clarity, resource availability, supervisor support, co-worker support, tenure and opportunities to study enhance the organisational commitment of academic staff (Joiner \& Bokalis, 2006). Rungruang (2012) found several antecedents of the organisational commitment of academic staff, which includes, among others, relationship with co-workers, support from the university, relationship with management and students, compensation, professional status and welfare benefits. Organisational commitment reduces academic staff members' intention to quit their jobs when organisational support and HRM practices (i.e. career development) are available (Hundera, 2014; Khan et al., 2014; Lew, 2010).

Based on the above, a hypothesised model for this study is presented in Figure 1.

This model leads to the following integrated hypothess for the study:

$\mathbf{H}_{1}$ : antecedents There would be a significant positive relationship between the antecedents of talent management (i.e. talent attraction and management support) and organisational commitment.

$\mathbf{H}_{2}$ : There would be a significant, positive relationship between talent management practices (i.e. talent development, compensation and recognition and institutional practices) and organisational commitment.

$\mathbf{H}_{3}$ : There would be a significant negative relationship between the antecedents of talent management (i.e. talent attraction and management support) and intention to quit.

$\mathbf{H}_{4}$ : There would be a significant negative relationship between talent management practices (i.e. talent development, compensation and recognition and institutional practices) and intention to quit.

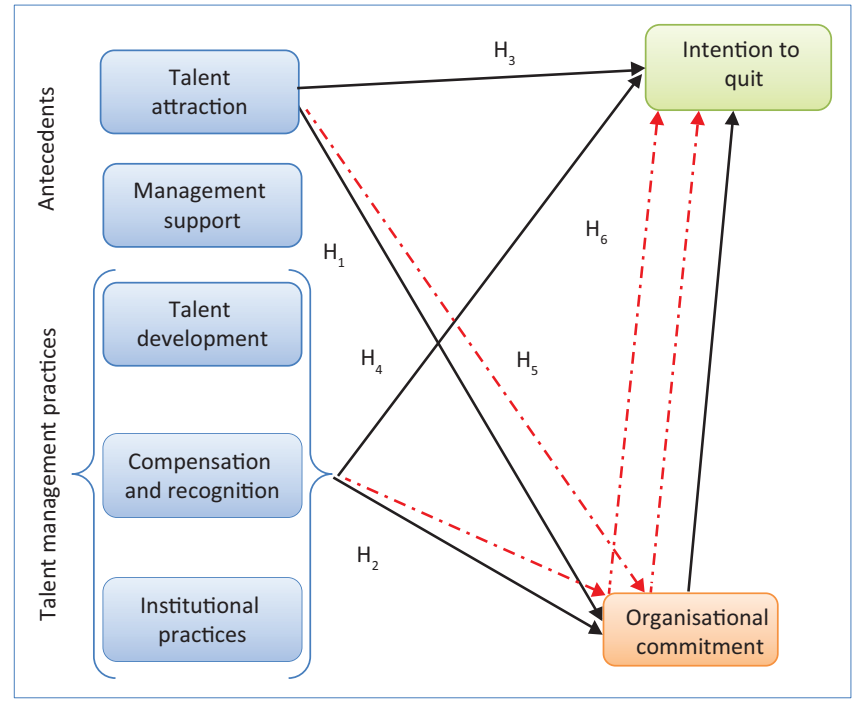

$\mathrm{H}$, hypothesis

FIGURE 1: Hypothesised model for the study.

$\mathbf{H}_{5}$ : Organisational commitment moderates the relationship between the antecedents of talent management (i.e. talent attraction and management support) and intention to quit.

$\mathbf{H}_{6}$ : Organisational commitment moderates the relationship between talent management practices (i.e. talent development, compensation and recognition and institutional practices) and intention to quit.

\section{Research design Research approach}

A quantitative research approach was followed in this study, using surveys to collect the data. This research was crosssectional in nature, which, according to Field (2009), is ideal for the testing of cause-and-effect relationships between variables.

\section{Research method}

\section{Research participants}

The respondents were academic staff from 11 public HEIs in South Africa. A total of 294 surveys were distributed to a purposive convenience sample of early career academics. A response rate of $40 \%(n=117)$ was achieved. Fifty-one point three per cent of the sample consisted of women, while male respondents made up $46.2 \%$ of the sample. The ethnicity of the sample was divided into $47.9 \%$ white, followed by black Africans (37.6\%), 7.7\% Indians and 3.4\% mixed race. The age group with the highest number of respondents was $40-49$ years (34.0\%), while, on an accumulative basis, $82.0 \%$ of the respondents were older than 40 years. The largest single group of respondents was those in possession of a master's degree (49.6\%), and, combined, $75.4 \%$ of the respondents had either a master's degree or a doctorate. The largest group of respondents was employed on the lecturer level $(54.7 \%)$, followed by the senior lecturer level $(33.3 \%)$. The majority of respondents had $0-5$ years' work experience in academia (53.0\%) and had been employed for 0-5 years in their current job (70.9\%). 


\section{Measuring instruments}

The following measurements were used in this study:

- Talent attraction: The Talent Attraction Scale was developed by the authors. The scale consists of 25 items and measures eight factors: opportunity to apply skills, career advancement, autonomy, job security, innovation, contribution, intellectual stimulation and worklife balance. Responses were measured on a five-point Likert scale ranging from strongly disagree (1) to strongly agree (6).

- Talent development: A talent development scale was developed by the authors. The talent development scale consists of 15 items, and measures three dimensions: opportunities for growth and development, influence in career decisions and role clarity. Responses were measured on a four-point Likert scale ranging from never (1) to always (4).

Talent retention factors were measured by following the talent retention diagnostic tool as developed by Theron et al. (2014). The tool consisted of the following four sections:

- Compensation and Recognition Scale: This section of the questionnaire measured nine items related to compensation and recognition on a six-point scale ranging from strongly disagree (1) to strongly agree (6). This questionnaire obtained an acceptable internal consistency of 0.882 .

- Management Support Scale: The respondents were requested to indicate how they rated their relationship with their immediate supervisor or direct line manager. Nine items referring to trust, communication, feedback, career development, communication and performance appraisals were presented, measured on a six-point scale ranging from strongly disagree (1) to strongly agree (6). This questionnaire obtained an acceptable internal consistency of 0.934 .

- Satisfaction with Institutional Practices Scale: This adapted questionnaire measured general satisfaction with institutional practices, that is, institutional leadership, values, strategies, communication, talent management (nine items) and satisfaction with research funding (four items). Responses were measured on a four-point Likert scale ranging from extremely dissatisfied (1) to extremely satisfied (4). This questionnaire obtained an acceptable internal consistency ranging from 0.783 to 0.923 .

- Intention to Quit Scale (Cohen, 1993). The questionnaire consisted of three items and assessed early career academics' intention to leave. Responses were measured on a six-point Likert scale ranging from strongly disagree (1) to strongly agree (6). Acceptable internal consistencies were obtained of above 0.90 for this in several South African studies.

- Organisational Commitment: The questionnaire consisted of 15 items and was developed by Allen and Meyer (1990) to measure affective, normative and continuous commitment. Responses were measured on a six-point Likert scale ranging from strongly disagree (1) to strongly agree (6). Acceptable internal consistencies were found for this measure (Sage, 2012).

\section{Research procedure}

Permission for the project was first obtained from the head of skills development of Higher Education South Africa.
The questionnaires for the research project were distributed via the skills development facilitators, in hard copy, to a purposive convenience sample of academics in the identified HEIs. Permission to use the questionnaires was obtained from the relevant developers and subjected to an ethical clearance process. Completed questionnaires were treated anonymously, to protect the identity of the respondents.

\section{Data analyses}

Data analyses were carried out with the aid of SPSS software (SPSS, 2016). Exploratory factor analyses were applied to determine the factor structure of the measurements. Cronbach's alphas were used to determine the reliability of the scale and its items. A cut-off point of 0.7 was used as a guideline for acceptable reliabilities (Field, 2009). Pearson correlation analyses were performed to test for the significance of relationships between the variables. Multiple regression analyses were applied to test for the moderating effect between the variables.

\section{Ethical consideration}

Ethical clearance for the research was provided by NorthWest University.

\section{Results}

\section{Factor and reliability analyses}

\section{Talent Attraction Scale}

Principal component analyses were performed on the 25 items of the Talent Attraction Scale. The initial results showed that eight factors could be extracted, based on the eigenvalues. A subsequent principal component analysis was performed using varimax rotation to specify eight factors. One item was deleted because of problematic loadings. The eight factors explained $75.087 \%$ of the variance and were labelled job security (Factor 1), autonomy (Factor 2), innovation (Factor 3), contribution (Factor 4), career advancement (Factor 5), intellectual stimulation (Factor 6), work-life balance (Factor 7) and opportunity to apply skills (Factor 8). The eight factors were subjected to a second-order factor analysis. Three factors (opportunity to apply skills, work-life balance and intellectual stimulation) were excluded because of low reliability loadings. The factor analysis resulted in one factor that explained $47.684 \%$ of the variance, which was labelled talent attraction. The career advancement factor was further excluded because of problematic loadings.

\section{Talent development scale}

Principal component analyses were performed on the 15 items of the Talent Development Scale. The initial results showed that three factors could be extracted based on the eigenvalues. A subsequent principal component analysis was performed using varimax rotation to specify three factors. Four items were deleted because of problematic loadings. The three factors explained $68.050 \%$ of the variance and were labelled role clarity (Factor 1), skill utilisation (Factor 2) and participation in career decisions (Factor 3). The three factors 
were subjected to a second-order factor analysis. The factor analysis resulted in one factor that explained $59.976 \%$ of the variance, which was labelled career development.

\section{Compensation and recognition}

Exploratory factor analysis using the principal component method was conducted on the nine items of the Compensation and Recognition Scale. The results showed one underlying factor that explained $53.514 \%$ of the variance. The item loadings were acceptable, ranging from 0.639 to 0.820 . The factor was labelled compensation and recognition.

\section{Management support}

An exploratory factor analysis using the principal component method was conducted on the nine items of the Management Support Scale. The results showed one underlying factor that explained $69.333 \%$ of the variance. The item loadings were acceptable, ranging from 0.865 to 0.901 . The factor was labelled management support.

\section{Satisfaction with institutional practices}

Exploratory factor analyses using the principal component method were performed on the 13-item measure. The results showed two underlying factors that explained $61.529 \%$ of the variance. The factors were labelled satisfaction with general institutional practices (Factor 1) and satisfaction with institutional funding opportunities (Factor 2). All items showed acceptable loadings, ranging from 0.520 to 0.856 . A second-order factor analysis was performed on the two factors. The factor analysis resulted in one factor that explained $73.261 \%$ of the variance, which was labelled satisfaction with institutional practices.

\section{Intention to quit}

Exploratory factor analysis using the principal component method was performed on the three-item measure. The results

TABLE 1: Descriptive statistics of the measurements.

\begin{tabular}{lccccc}
\hline Variable & Mean & SD & Skewness & Kurtosis & $\alpha$ \\
\hline Talent attraction & 4.4450 & 0.71288 & -0.043 & -0.493 & 0.832 \\
Career development & 2.8993 & 0.52820 & -0.313 & 0.666 & 0.863 \\
Compensation and recognition & 3.4065 & 1.10959 & -0.176 & -0.667 & 0.890 \\
Management support & 4.2612 & 1.20489 & -0.841 & -0.071 & 0.942 \\
Institutional practices & 2.7415 & 0.53072 & -0.260 & 0.241 & 0.913 \\
Intention to quit & 2.9459 & 1.59918 & 0.518 & -0.829 & 0.861 \\
\hline Organisational commitment & 4.3846 & 0.84478 & -0.988 & 1.957 & 0.857 \\
\hline
\end{tabular}

SD, standard deviation. showed one underlying factor that explained $85.478 \%$ of the variance. The factor was labelled intention to quit.

\section{Organisational commitment}

Exploratory factor analysis using the principal component method was conducted on the 15-item measure. Four items were deleted because of problematic loadings. The results showed one underlying factor that explained $85.478 \%$ of the variance. The factor was labelled organisational commitment.

Descriptive statistics of the measurements are reported in Table 1.

The results in Table 1 show very good to excellent reliabilities for the measurements, where the guideline is $\alpha \geq 0.70$. The respondents were in agreement that talent attraction factors, management support and career development opportunities were available. Respondents were slightly satisfied with compensation and recognition and institutional practices. About half of the participants (49\%) considered quitting their institution. Most the participants appeared to be committed to their respective institutions.

Next, the results of testing of the hypotheses are reported.

\section{Testing of hypotheses}

The results of the Pearson correlations are reported in Table 2.

The results in Table 2 show that compensation and recognition is significantly positively related to organisational commitment (medium effect) and negatively related to intention to quit (large effect). Management support is significantly positively related to organisational commitment (medium effect) and significantly negatively related to intention to quit (small effect). Institutional factors are significantly positively related to organisational commitment (large effect) and significantly negatively related to intention to quit (medium effect). Talent development is significantly positively related to organisational commitment (medium effect) and significantly negatively related to intention to quit (small effect). Talent attraction is significantly positively related to intention to quit (medium effect). Organisational commitment is significantly negatively related to intention to quit (large effect).

The above results partially confirm Hypotheses 1, 2, 3 and 4, that the antecedents of talent management (such as

TABLE 2: Pearson correlation analyses between variables.

\begin{tabular}{|c|c|c|c|c|c|c|c|}
\hline Variables & 1 & 2 & 3 & 4 & 5 & 6 & 7 \\
\hline Remuneration and recognition & 1.000 & - & - & - & - & - & - \\
\hline Management support & $0.429 * \dagger$ & 1.000 & - & - & - & - & - \\
\hline Institutional factors & $0.572 * \ddagger$ & $0.355 * \dagger$ & 1.000 & - & - & - & - \\
\hline Career development & $0.319 * \dagger$ & $0.524 *+$ & $0.341 * \dagger$ & 1.000 & - & - & - \\
\hline Talent attraction & -0.030 & 0.038 & 0.084 & 0.121 & 1.000 & - & - \\
\hline Organisational commitment & $0.487^{*} \dagger$ & $0.333 * \dagger$ & $0.621 * \vdots$ & $0.402 * \dagger$ & 0.103 & 1.000 & - \\
\hline Intention to quit & $-0.529 *+$ & $-0.277 *$ & $-0.486 * \dagger$ & $-0.253^{*}$ & $0.319 * \dagger$ & $-0.638 * \dagger$ & 1.000 \\
\hline
\end{tabular}

*, Statistically significant: $p \leq 0.01$

$\dagger$, Practically significant correlation (medium effect): $r \geq 0.30$; $\$$ Practically significant correlation (large effect): $r \geq 0.50$. 
management support, talent development, compensation and institutional practices) can enhance organisational commitment and reduce turnover intentions of early career academics. No significant relationships were found between talent attraction, organisational commitment and turnover intentions.

Next, the multiple regression analyses for the interactive relationship of organisational commitment as moderator are presented. All the independent variables were centred. In Models 1 and 2, the effects of the independent variables were entered, while in the third model the interaction term was also entered. The results are reported in Table 3.

The results in Table 3 show no significant relationship when adding organisational commitment as moderator in the interactive relationship between talent attraction, talent development, compensation and recognition, management support, institutional factors and intention to quit. Organisational commitment, therefore, does not moderate the relationships between these variables.

Based on these results, Hypotheses 5 and 6 are rejected.

\section{Discussion}

The main objective of this research was to explore the causal relationships between the antecedents and consequences of talent management for early career academics in public South African HEIs. The antecedents were identified as talent attraction factors and management support, and the consequence factors were identified as organisational commitment and intention to quit. Talent management practices (i.e. talent development, compensation and recognition and institutional practices) were used as moderating factors between the antecedent and consequence factors

The results showed no significant relationship between talent attraction factors and organisational commitment. In contrast with previous studies (see Matata, Elegwa, \& Maurice, 2014; Mohamed \& El-Shaer, 2013), the availability of talent attraction factors in this study will not influence positive organisational behaviours such as the organisational commitment of early career academics. Talent attraction was significantly positively related to turnover intentions of the participants. This is an interesting finding, as one would expect early career academics to remain within HEIs when talent attraction practices are available. However, it is worth mentioning that almost half of the respondents in this study considered quitting their jobs.

In this study it was evident that early career academics perceived high levels of management commitment towards talent management in their respective institutions. The availability of management support enhanced the organisational commitment of the early career academics in this sample and reduced their turnover intentions. The presence of management support for talent management in this study is an indicator that early career academics are considered as important drivers for the execution of the business strategy of HEIs (see Armstrong, 2006; Garrow \& Hirsch, 2008). In line with previous studies, the results

TABLE 3: Multiple regression analyses with organisational commitment as moderator between variables.

\begin{tabular}{|c|c|c|c|c|c|c|c|c|}
\hline \multirow[t]{2}{*}{ Model } & \multicolumn{2}{|c|}{ Un-standardised coefficients } & \multirow{2}{*}{$\begin{array}{l}\text { Standardised coefficients } \\
\text { (beta) }\end{array}$} & \multirow[t]{2}{*}{$t$} & \multirow[t]{2}{*}{$p$ (sig.) } & \multirow[t]{2}{*}{$\boldsymbol{R}$} & \multirow[t]{2}{*}{$R^{2}$} & \multirow[t]{2}{*}{$\Delta R^{2}$} \\
\hline & B & SE & & & & & & \\
\hline \multicolumn{9}{|c|}{ Remuneration, organisational commitment and intention to quit } \\
\hline (Constant) & 7.012 & 1.531 & - & 4.580 & 0.000 & 0.689 & 0.475 & 0.461 \\
\hline Remuneration & 0.109 & 0.512 & 0.076 & 0.213 & 0.831 & - & - & - \\
\hline Commitment & -0.598 & 0.363 & -0.316 & -1.648 & 0.102 & - & - & - \\
\hline REM $\times$ COM & -0.118 & 0.113 & -0.484 & -1.046 & 0.298 & - & - & - \\
\hline \multicolumn{9}{|c|}{ Management support, organisational commitment and intention to quit } \\
\hline (Constant) & 7.089 & 1.492 & - & 4.752 & 0.000 & 0.640 & 0.418 & 0.402 \\
\hline Management support & 0.267 & 0.372 & 0.201 & 0.718 & 0.474 & - & - & - \\
\hline Commitment & -0.822 & 0.365 & -0.434 & -2.256 & 0.026 & - & - & - \\
\hline MANXCOM & -0.088 & 0.087 & -0.382 & -1.016 & 0.312 & - & - & - \\
\hline \multicolumn{9}{|c|}{ Institutional factors, organisational commitment and intention to quit } \\
\hline (Constant) & 7.759 & 2.022 & - & 3.838 & 0.000 & 0.650 & 0.422 & 0.407 \\
\hline Institutional factors & -0.047 & 0.844 & -0.016 & -0.056 & 0.956 & - & - & - \\
\hline InsXCom & -0.092 & 0.186 & -0.228 & -0.492 & 0.623 & - & - & - \\
\hline \multicolumn{9}{|c|}{ Talent attraction, organisational commitment and intention to quit } \\
\hline (Constant) & 0.462 & 3.243 & - & 0.142 & 0.887 & 0.751 & 0.565 & 0.553 \\
\hline Talent attraction & 1.826 & 0.722 & 0.814 & 2.528 & 0.013 & - & - & - \\
\hline Commitment & -0.292 & 0.748 & -0.154 & -0.391 & 0.697 & - & - & - \\
\hline TalentAttractionXCom & -0.223 & 0.166 & -0.713 & -1.344 & 0.181 & - & - & - \\
\hline \multicolumn{9}{|c|}{ Talent development, organisational commitment and intention to quit } \\
\hline (Constant) & 4.457 & 2.167 & - & 2.057 & 0.042 & 0.652 & 0.425 & 0.410 \\
\hline Talent development & 1.436 & 0.806 & 0.474 & 1.783 & 0.077 & - & - & - \\
\hline Commitment & -0.314 & 0.508 & -0.166 & -0.619 & 0.537 & - & - & - \\
\hline TalentDevXCom & -0.333 & 0.181 & -0.801 & -1.846 & 0.068 & - & - & - \\
\hline
\end{tabular}

Sig, significance; SE, standard error; $t, t$ test statistics; $p$, probability value; $R$, correlation coefficient; $R^{2}$, coefficient of determination; $\Delta R^{2}$, adjusted coefficient of determination. 
confirm that management support can have positive workrelated outcomes for novice scholars (see Joiner \& Bokalis, 2006; Matata et al., 2014) and plays an important role in the retention of this occupational group (Hundera, 2014).

The results further show that talent management factors such as talent development, compensation and recognition and satisfaction with institutional practices are significantly positively related to organisational commitment of early career academics. In line with other research findings, opportunities for career development, adequate remuneration and recognition and support from the university will enhance positive work-related behaviours such as the organisational commitment of early career academics (Rungruang, 2012). The present study also confirms that the availability of talent management practices will reduce the turnover intentions of academics (see Hundera, 2014). No moderating relationships were found in this study.

\section{Practical implications}

The results of this research lend themselves to several practical applications for HEIs to manage early career talent more effectively. The results showed that management support for talent is an important antecedent variable that reinforces positive work-related behaviours such as organisational commitment and reduces the turnover intentions of early career academics. The availability of management support towards talent in this study provides an opportunity for human resource practitioners to develop academic talent management strategies that are aligned with the business strategy of higher education. Although the management support towards talent in this study seemed promising, further results emphasised the need to improve the career development prospects and compensation and recognition practices for early career academics. Talent management entails a strategic integrated process whereby the complete talent life-cycle of academics needs to be managed effectively from start to finish.

\section{Limitations and recommendations}

This research had some limitations. Firstly, a cross-sectional research approach was followed whereby responses were collected at one point in time. Given the current changing situation of HEIs, these perceptions are likely to change over the long term. Therefore longitudinal research should be applied to detect turnover intentions of early career academics over the long term. Secondly, this research only focused on early career academics. As a result the findings cannot be generalised to other academic job levels.

For future research it is recommended that the sample size be expanded to other academic job levels to do a comparative analysis on the antecedents and consequences of all academic cohorts in higher education. This research should also be expanded to include higher education management and HRM departments to obtain a more holistic stakeholder perspective on talent management and how it can best be aligned with the business strategy. Future studies can also benefit from applying mixed method research methodologies. This research yielded some interesting results, which could further be explained by follow-up interviews or focus groups.

\section{Conclusion}

In conclusion, this research presented an overview of the factors that can advance and constrain the effective talent management of early career academics in South African HEIs and the potential outcomes thereof. The results of this research suggest that HEIs need to focus on the redesign of compensation and recognition practices, as well as training and development initiatives, to reduce the turnover intentions of early career academics. This research again highlighted the importance of management support and commitment towards talent management initiatives.

\section{Acknowledgements Competing interests}

The authors declare that they have no financial or personal relationships that may have inappropriately influenced them in writing this article.

\section{Authors' contributions}

D.L.L is a PhD student - this article is based on her PhD thesis and she compiled the article. N.E.B. was the supervisor for this study and N.E.S. the co-supervisor. Both supervisors provided editorial inputs for the article.

\section{References}

Allen, N. J. \& Meyer, J. P. (1990). The measurement and antecedents of affective, continuance and normative commitment to the organization. Journal of Occupational Psychology, 63, 1-18. https://doi.org/10.1111/j.2044-8325.1990. tb00506.x

Archer, S. (2017). The function of a university in South Africa: Part 1. South African Journal of Science, 113(5/6), 1-6. https://doi.org/10.17159/sajs.2017/a0190

Armstrong, M. (2006). Armstrong's handbook on human resource management practice (11th ed.). London: Kogan Page.

Barkhuizen, E. N. (2014). Project talent management. In Y. Du Plessis (Ed.), Project management: A behavioural perspective: Theoretical principles, advanced practices and cases. Pearson Education (Chapter 13, pp. 370-408). ISBN 9781775 84951.

Barkhuizen, E. N. (2015, March). Talent Management: The catalyst for the 21st century business world. Inaugural lecture at North-West University. Retrieved from http:// www.nwu.ac.za/sites/www.nwu.ac.za/files/files/mc/documents/2015\%20-\%20 www.nwu.ac.za/sites/www.nwu.ac.za/files/files/mc/docume
INAUGURAL\%20LECTURE\%2OPROF\%20BARKHUIZEN.pdf

Barkhuizen, E. N., Diseko, E., \& Schutte, N. E. (2015). The relationship between talent management and turnover intentions of teachers in Botswana. Proceedings of the 20th International Academic Conference, Madrid, Spain, pp. 37-47. ISBN 978-8087927-17-5.

Barkhuizen, E. N., \& Rothmann, S. (2006). Work engagement of academic staff in South African higher education institutions. Management Dynamics, 15, 38-48.

Barkhuizen, E. N., \& Schutte, N. E. (2016, April). The development of a talent life cycle for government institutions. Paper presented at World Business Conference, London, UK.

Barkhuizen, E. N., Schutte, N. E., \& Nagel, L. (2017). Talent management, organisational satisfaction and turnover intentions of academic staff. In N. Delener, L. \& C. Schweikert (Eds.), 19th Global Business and Technology Association Conference, Vienna, Austria, pp. 22-30. Gbata, NY. ISBN: -932917-13-6.

Barkhuizen, E. N., \& Stanz, K. J. (2010). Linking organisational energy and individual well-being: The Influence of Leader's Talent Mindset. Paper Published in the Peer Reviewed Conference Proceedings of the 12th Annual Conference of Global Business and Technology Association, Kruger National Park, South Africa, 5-9 July, pp. 50-57, Gbata, USA. ISBN: 1-932917-06-3.

Barkhuizen, E. N., Welby-Cooke, G., Schutte, N. E., \& Stanz, K. J. (2014). Talent management and leadership reciprocity: The case of the South African aviation industry. Mediterranean Journal of Social Sciences, 5(9), 11-17. 
Bazeley, P. (2003). Defining 'Early Career' in research. Higher Education, 45(3), 257279. https://doi.org/10.1023/A:1022698529612

Bitzer, E. M. (2008). The professoriate in South Africa: Potentially risking status inflation. South African Journal of Higher Education, 22, 265-281.

Bitzer, E. M. (2009). Higher education in South Africa: A scholarly look behind the scenes. Stellenbosch, South Africa: Sun Media.

Bosanquet, A., Mailey, A., Matthews, K. E., \& Lodge, J. M. (2017). Redefining 'early career' in academia: A collective narrative approach. Higher Education Research and Development, 36(5), 890-902. https://doi.org/10.1080/07294360.2016.1263934

Botha, A., Bussin, M., \& De Swart, L. (2011). An employer brand predictive model for talent attraction and retention. South African Journal of Human Resource Management, 9(1), 1-12. https://doi.org/10.4102/sajhrm.v9i1.388

Busch, R., \& Ledingham, M. (2016). Bothered bloggings and troubled tweets: Constructions of stress and concerns for early-career academics. First International Conference on Advanced Business and Social Sciences, (pp. 1-12). University of Notre Dame, Australia.

Cohen, A. (1993). Work commitment in relation to withdrawal intentions and union effectiveness. Journal of Business Research, 26, 75-90. https://doi.org/10.1016/ 0148-2963(93)90044-P

Department of Higher Education. (2015). Staffing South Africa's universities framework. A comprehensive, transformative guide to developing future generations of academics and building capacity. Department of Higher Education, Pretoria, South Africa.

De Villiers, A. P., \& Steyn, A. G. W. (2009). Effect of changes in state funding of highe education output in South Africa: 1986-2007. South African Journal of Higher Education, 22, 43-68. https://doi.org/10.4314/sajhe.v23i1.44801

Erasmus, B. J., Grobler, A., \& van Niekerk, M. (2015). Employee retention in a higher education institution: An organisational development perspective. Progression 37(2), 32-62. https://doi.org/10.25159/0256-8853/600

Field, A. (2009). Discovering statistics using SPSS (2nd ed.). London: Sage.

Gale, H. (2011). The reluctant academic: Early career academics in a teaching oriented university. International Journal for Academic Development, 3, 215-227. https:// doi.org/10.1080/1360144X.2011.596705

Garrow, V., \& Hirsh, W. (2008). Talent management: Issues of focus and fit. Public Personne Management, 37, 389-402. https://doi.org/10.1177/009102600803700402

Higher Education South Africa. (2014). Remuneration of academic staff at South African universities: A summary report of the HESA statistical study of academic remuneration. Higher Education South Africa, Pretoria, South Africa.

Hundera, M. B. (2014). Factors affecting academic staff turnover intentions and the moderating effect of gender. International Journal of Research in Business Management, 2(9), 57-70.

Joiner, T. A., \& Bokalis, S. (2006). The antecedents of organisational commitment: The case of Australian causal academics. International Journal of Educational Management, 20(6), 439-452. https://doi.org/10.1108/09513540610683694

Khan, I., Nawaz, A., Khan, S., Khan, F., Khan, M. S., Yar, N. B. (2014). The impact of organisational commitment on the intention to leave among academicians in higher education institutions in Pakistan. International Journal of Academic Research in Business and Social Sciences, 24(2), 243-254.

Kontoghiorghes, C., \& Frangou, K. (2009). The association between talent retention, antecedent factors and consequent organizational performance. SAM Advanced Management Journal, 74(1), 29-58.

Lew, T. Y. (2010). Affective commitment and turnover intention of academics in Malaysia. Proceedings of International Conference on Business and Economics Research, 1(1), 110-114.

Magolego, H., Barkhuizen, E. N., \& Lesenyeho, D. L. (2013). Talent management and job performance: The mediating role of job satisfaction. In S. M. Lee \& G. Roodt (Eds.), 30th Pan Pacific Conference, Johannesburg, South Africa (pp. 132-135). Pan Pacific Business Association, China. ISBN: 1-931649-27-3.

Makondo, L. (2014). Academics attraction and retention trends at a South African university. Journal of Sociology Anthropology, 5(2), 169-177. https://doi.org/10.1 080/09766634.2014.11885621

Matata, K., Elegwa, K., \& Maurice, S. (2014). Job-related factors and their influence on organisational commitment of part-time academic staff in institutions of higher education in Nairobi and Mombasa cities in Kenia. International Journal of Business and Social Science, 5(8), 110-119.

McAlpine, L. \& Akerlind, G. (2010). Becoming and academic: International perspectives, Basingstoke, Palgrave Macmillan.

McArdle, S. \& Ramerman, J. (2008). Strategic talent management. Retrieved from http://www.managesmarter.com/msg/content_display/training/e3i826839942 e5a637a4e243acf654f6e48

Mohamed, L. K., \& El-Shaer, A. M. (2013). Professional commitment and perceived organisational support among nursing academic staff: A comparative study. The organisational support among nursing academic ste
Medical Journal of Cairo University 81(1), 235-243.

Mokgojwa, D., Barkhuizen, E. N., \& Schutte, N. E. (2017). The development of a talent risk management tool for academics in South African education institutions. In N. Delener, L. \& Schweikert, C. (Eds.), 19th Global Business and Technology Association Conference, Vienna, Austria (pp. 553-539). New York, USA, Gbata. ISBN: -932917-13-6.
Mouton, N., Louw, G. P., \& Strydom, L. P. (2013). Present-day dilemmas and challenges of the South African Tertiary system. International Business and Economics Research Journal, 12(3), 285-300.

Mpofu, L., \& Barkhuizen, E. N. (2013). The impact of talent management practices on employees in a government institution. In S. M. Lee \& G. Roodt (Eds.), 30th Pan Pacific Conference, Johannesburg, South Africa (pp. 129-131). PPBA. ISBN: 1-931649-27- 3.

Mukweyi, A. S. (2016). An investigation of the influence of talent management practices on the retention of healthcare professionals at Kijabe Mission Hospital, Kiambu. Unpublished Doctoral thesis, Strathmore Business School, Strathmore University, UK.

Munsamy, M., \& Bosch Venter, A. (2009). Retention factors of management staff in the maintenance phase of their careers in local government. SA Journal of Human Resource Management/SA Tydskrif vir Menslikehulpbronbestuur, 7(1), Art. \#198 1-9. https://doi.org/10.4102/sajhrm.v7i1.198

Myburgh, H. (2015). White Paper: Talent Attraction. Strategic Staffing Solutions. Retrieved from www.dav.co.za

Ntshoe, P., Higgs, L. G., Higgs, C. C., \& Wolhuter, I. (2008). The changing academic profession in higher education and new managerialism and corporatism in South Africa. South African Journal of Higher Education, 22(2), 391-403. https://doi. Africa. South African Journal of
org/10.4314/sajhe.v22i2.25793

O'Callaghan, A. (2008). Talent management review. Fasset, SETA. Retrieved from http:// www.fasset.org.za/downloads/events/talent_man_sdf_long_article_website.pdf

Onah, F. O., \& Anikwe, O. S. (2016). The task of attraction and retention of academic staff in Nigeria universities. Journal of Management and Strategy, 7(2), 9-20. https://doi.org/10.5430/jms.v7n2p9

Pienaar, C., \& Bester, C. (2008). Addressing career obstacles within a changing higher education work environment: Perspectives of academic. South African Journal of Psychology, 39(3), 376-385. https://doi.org/10.1177/008124630903900311

Pienaar, Y. (2013). A structured model of the relationship between talent mindset, organizational energy and work wellness. (Unpublished Doctoral dissertation). Department of Human Resource Management, University of Pretoria, South Africa.

Porter, L. W., Steers, R. M., Mowday, R. T., \& Boulian, P. V. (1974). Organizationa commitment, Job satisfaction, and turnover among psychiatric technicians. Journal of Applied Psychology, 59, 603-609.

Price, E., Coffey, B., \& Nethery, A. (2015). An early career academic network: What worked and what didn't. Journal of Further and Higher Education, 39(5), 680-698. https://doi.org/10.1080/0309877X.2014.971106

Robyn, A., \& Du Preez, R. (2013). Intention to quit amongst Generation Y academics at higher education institutions. SA Journal of Industrial Psychology, 39(1), 1-14. https://doi.org/10.4102/sajip.v39i1.1106

Rungruang, P. (2012). Antecedents of organisational commitment of academics in Thailand: Qualitative analyses. Research Journal of Business Management, 6(2), 1-12.

Sage, N. (2012). The effect of expatriate salary on host country nationals in South Africa: A study involving perceived compensation disparity, organisational commitment and job satisfaction. (Unpublished Masters Dissertation). Department of Human Resource Management, University of Pretoria, South Africa.

Saurombe, M. (2017). Management perspectives on a talent value proposition for academic staff in a South African Higher Education Institution. (Unpublished Doctora dissertation). Department of Industrial Psychology, North-West University, Mmabatho.

Saurombe, M., Barkhuizen, E.N., \& Schutte, N.E. (2017). Management perceptions of a higher educational brand for the attraction and of talent academic staff. South African Journal of Human Resource Management, 15, 1-10.

Schlecther, A. F., Syce, C., \& Bussin, M. (2016). Predicting voluntary turnover in employees using demographic characteristics: A South African case study. Acto Commercii, 16(1), 1-10. https://doi.org/10.4102/ac.v16i1.274

Schutte, N. E. (2015). The development of a diagnostic tool for the assessment of competencies for human resource management practitioners in South Africa. (Unpublished Doctoral Dissertation). Department of Industrial Psychology, NorthWest University, Mmabatho.

Selesho, J. M., \& Naile, I. (2014). Academic staff retention as a human resource factor: University perspective. International business \& Economic Research Journal 13(2), 295-303. https://doi.org/10.19030/iber.v13i2.8444

Singh, R. J. (2015). Current trends and challenges in South African higher education South African Journal of Higher Education, 29(3), 1-7.

Smit, W., Stanz, K., \& Bussin, M. (2015). Retention preferences and the relationship between total rewards, perceived organisational support and perceived supervisor support. SA Journal of Human Resource Management/SA Tydskrif vir Menslikehulpbronbestuur, 13(1), Art. \#665, 1-13. https://doi.org/10.4102/ Menshrm.v13i1.665

SPSS Inc. (2016). SPSS 23 for Windows. Chicago, IL: SPSS Inc.

The South African Council on Higher Education. (2014). Annual Report 2013/4. The South African Council on Higher Education.

Theron, M., Barkhuizen, E. N., \& Du Plessis, Y. (2014). Managing the academic talent void: Investigating factors in academic turnover and retention in South Africa. South African Journal of Industrial Psychology, 40(1), 1-14. https://doi.org/ 10.4102/sajip.v40i1.1117

Veldman, G. (2011). The impact of talent management practices on the retention of employees. (Unpublished Masters dissertation). University of Pretoria, South Africa. 